\title{
A Two-Stage Power Converter for Welding Applications with Increased Efficiency and Reduced Filtering
}

\author{
Christian Klumpner Mathew Corbridge \\ University of Nottingham, School of Electrical and Electronic Engineering \\ University Park, Nottingham, NG7 2RD, United Kingdom \\ E-mail: klumpner@ieee.org
}

\begin{abstract}
The power supply technology used in welding applications changed dramatically from manually tap-controlled $50 \mathrm{~Hz}$ bulky transformers which had large leakage inductance to provide stable arc burn to switch-mode fast controlled highfrequency power electronics. Nowadays, the typical converter configuration consist of a diode rectifier supplying via a large electrolytic capacitor a smooth DC-link voltage to a high switching frequency $\mathrm{H}$-bridge inverter that steps down the voltage and provides isolation via a high frequency transformer whilst operating with adjustable dutycycle to maintain the output current constant. This topology allows for important size reduction since the size of magnetics decreases rapidly with the increase of the frequency. This paper proposes a more complex two-stage configuration with a buck DC/DC converter operating at a reduced switching frequency to feed adjustable voltage to an $H$-bridge inverter, which is operating always with the required voltage at $50 \%$ dutycycle, enabling in addition the minimization of the output filter size and of the switching losses.
\end{abstract}

\section{INTRODUCTION}

The conventional Welding is integral part of construction, manufacturing and maintenance industries. In a study by the American Welding Society, Edison Welding Institute and US Department of Commerce in 2002, welding-related production costs were $\$ 30.4$ billion. This figure represents an aggregated $1.4 \%$ of the total production costs across all industry. With regard to welding related energy costs, welding represents $1.5 \%$ of the total industry energy cost, at $\$ 1.1$ billion [1]. This is a significant part of the production cost in each industry

"In electric arc welding, the melting energy is provided by establishing an arc between two electrodes, one of which is the metallic workpiece being welded" [2]. There are various technologies for welding, a few are named below: Shielded Metal Arc Welding (SMAW), Gas Metal Arc Welding (GMAW)/Metal Inert Gas (MIG), Flux-Cored Arc Welding (FCAW), Gas Tungsten Arc Welding (GTAW)/Tungsten Inert Gas (TIG), Submerged Arc Welding (SAW), Plasma Arc Welding (PAW).

\section{A. Voltage and current characteristics}

A constant-current characteristic is used when the arc length is controlled by the welder, e.g. in TIG welding. If the arc length is unintentionally varied, the arc voltage changes to maintain current.
MMA welding uses a drooping characteristic where it is advantageous to have a short circuit current higher than the normal load current to prevent the electrode from sticking to the workpiece when striking the arc. When compared to the straight characteristic, it has a comparatively higher no-load voltage, which is necessary when welding with $\mathrm{AC}$ in order to keep the arc from extinguishing too easily.

A constant-voltage characteristic maintains good control of the arc length when welding with continual wire filler feed. The rate at which the filler wire is fed dictates the current. Both MIG and SAW processes operate off this characteristic.

A dynamic characteristic needs to be used if there are rapid changes, i.e. short arc welding. This often includes an inductor on the output. The aim is to achieve a high, steady shortcircuiting frequency [3].

The static characteristics of a power supply suited for welding application is characterized by a no-load voltage large enough to initiate the arc burning (typically 50-60V) and a range where the supply has to deliver constant-current, where typically the voltage is less than $50 \%$ the no-load voltage (typically 20-30V), as depicted in Fig. 1.

The voltage drooping behavior is necessary to provide stable burn of the electric arc, which in older manually tap-changed power supplies relying on $50 / 60 \mathrm{~Hz}$ transformers were realized by building the transformer with a large airgap, which maximized the amount of shortcircuit impedance. However, this had the opposite effect that the power quality of such an equipment was poor (large reactive current consumed) and its size was large.

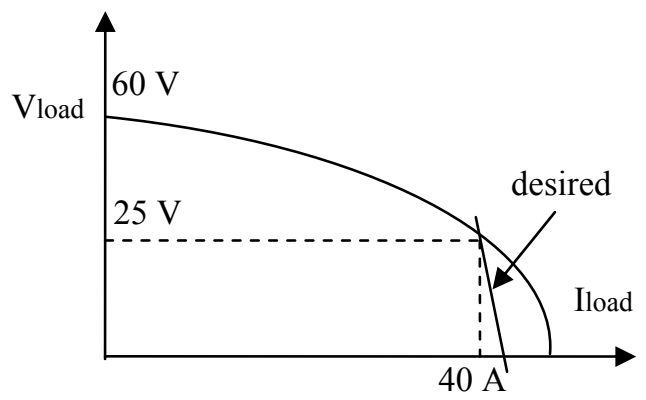

Fig. 1. V-A characteristic of a welding power supply. 
It is desired that the power supply to limit the current steeply near the maximum arc current, as depicted in the Fig. 1, rather than rely only on the current limitation capability offered by the shortcircuit impedance of the power supply/transformer at higher currents, the magnetic circuit will tend anyway to saturate. This is useful especially in situations where a shortcircuit is caused by the electrode touching the metal to be welded.

\section{B. Welding power supply topologies}

A traditional welding power supply has a large $50 \mathrm{~Hz}$ step down transformer that is connected to the AC mains. An isolation transformer is required as a safety precaution because the workpiece is actually part of the circuit, and needs to be connected eventually to earth. The transformer had a large leakage inductance in order to provide a stable welding arc.

Welding transformers are relatively inefficient when operating at grid frequencies $(50$ and $60 \mathrm{~Hz})$. Due to the large resulting current ripple of low frequency (multiple the supply frequency) from the converter, a large (extra weight and size) inductor is required. Most of these types of transformers weigh approximately 400 pounds and are a 32 inch box [4].

There are three solutions that would allow automatic adjustment of the output voltage/current in conjunction with a low frequency transformer, involving one of the following in the secondary side of a 50/60 Hz transformer: i) a thyristor controlled bridge; ii) a series type regulator or iii) a switchmode $\mathrm{dc} / \mathrm{dc}$ converter connected on the secondary side, with only the last one being able to provide fast control and maintain a reasonable efficiency and low size of the output filter inductor.

Alternatively, a high frequency converter could be used [5][9]. More advanced power electronic technologies, such as resonant converters to eliminate the switching losses whilst operating at very high switching frequencies, thus minimizing passive component size or to employ active front end solution to improve the power quality on the supply side have been investigated. There is a typical configuration of the power converter topology as shown in Fig. 2: a diode rectifier bridge (not shown) that converts the $\mathrm{AC}$ voltage into $\mathrm{DC}$ which is then smoothed by a DC-link capacitor; this is further inverter by a DC-to-high frequency AC inverter operating typically above the audible frequency range $(>20 \mathrm{kHz})$ and stepped down to an appropriate voltage level by a high frequency transformer, later rectified by a high frequency diode rectifier which feeds the current to the load via an output inductor.

The operation at high frequency allows the transformer to be reduced in size compared to a $50 / 60 \mathrm{~Hz}$ one, because of the EMF equation (given here for a sinusoidal waveform profile):

$$
E=\frac{2 \pi f N a B}{\sqrt{2}}=4.44 f N a B
$$

By increasing the frequency, the number of windings per volt (N/E) which is proportional to the amount of copper used in the windings and $a$, the core cross-section which is a measure of the core size, can to be reduced. By operating at higher frequencies, transformers can be physically much smaller (even though appropriate core materials tend to have smaller saturation flux density B such as ferrite need to be used) the core is able to transfer more power without reaching saturation, and fewer turns in the windings (thus smaller resistance of the primary and secondary windings), are needed. However, core specific loss $[\mathrm{W} / \mathrm{kg}]$ and conductor skin effect, also increase with the frequency. The advantages of the high frequency converter are: reduced weight and size, because of a smaller transformer, and a smaller inductor needed to smooth the output current ripple. The arrangement has an efficiency of 85$90 \%$ [2]. If the switching frequency is sufficiently high, the output is very steady without the traditional ripple of multiple the supply frequency [4] and by having a smaller output voltage ripple, an important reduction in the size of the output filter inductor is possible.

More recently power supplies have incorporated higher frequency DC/DC converters operating typically above the audible frequency range. By removing the transformer from the $50 \mathrm{~Hz}$ AC mains, the displacement power factor seen by the grid is much improved which is important due to the legislation concerning the harmonic content of the current drawn from the grid. The converter is controlled by adjusting the duty-cycle that alters the rectified voltage such that it maintains a constant load current to give a very stable arc burn. Welding equipments operating at a higher frequency would improve performance and quality of the welding and generate cost and space savings. These savings are due to the reduced number or turns required to manufacture the transformer which reduces the size and uses less copper, which is a quite expensive material.

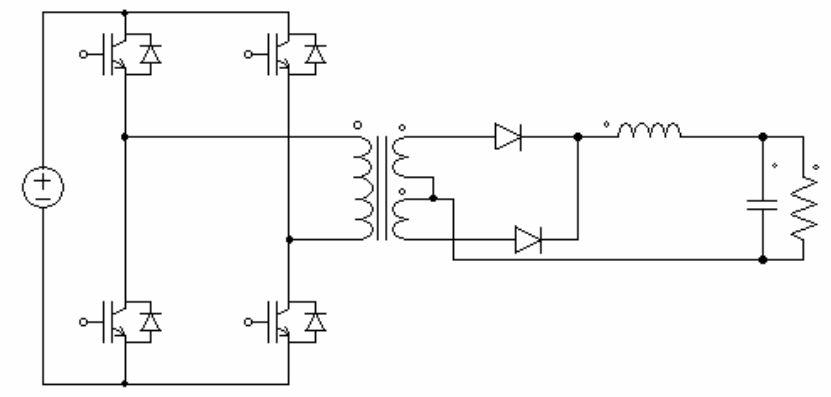

Fig. 2. Standard topology of the DC/DC converter used in welding application employing an $\mathrm{H}$-bridge inverter (rectifier stage omitted).

\section{THE PROPOSED CIRCUIT}

The proposed power supply consists of a two-stage arrangement with single switch buck converter connected to the H-bridge inverter as shown in Fig. 3. The benefits of twostage voltage source inverter topologies have been investigated in [10]. As the only requirement for the first stage buck converter is to provide adjustable voltage across the H-bridge DC-link capacitor, the buck transistor it is operated with a lower switching frequency (i.e. $5 \mathrm{kHz}$ ) and variable duty cycle while the high frequency full-bridge converter operates at an 
ultrasonic frequency and constant duty cycle, which means the components in the H-bridge inverter and the efficiency is optimized in order to produce on the output the required voltage.

The buck converter steps down the voltage and current across the H-bridge converter thereby reducing the total power losses experienced by the high frequency switching insulatedgate bipolar transistors (IGBTs).

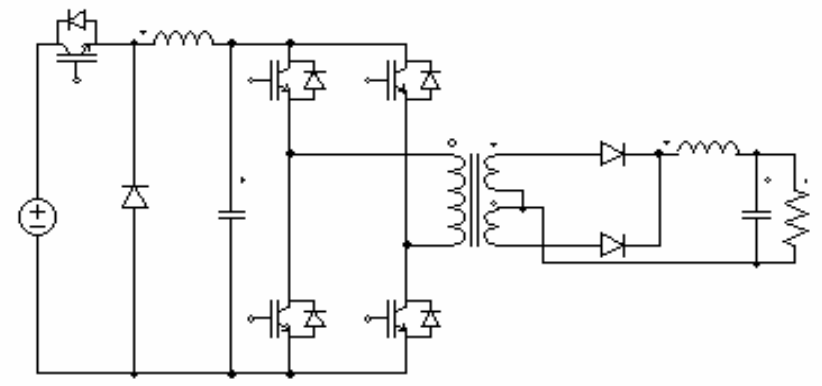

Fig. 3. The proposed two-stage DC/DC converter topology.

A PI controller can be used to control the output current by adjusting the H-bridge duty-cycle in the standard single stage H-bridge inverter system. For the proposed system, the switches in the two legs of the H-bridge inverter are gated in opposition (50\% dutycycle), whilst the duty-cycle of the buck converter is controlled by the output of the PI controlled.

\section{Simulation RESUltS}

The rectified voltage in a $415 \mathrm{Vrms} / 50 \mathrm{~Hz} 3$-phase voltage system is $585 \mathrm{~V}$. In order to provide a no-load voltage of $55 \mathrm{~V}$ on the output side of the welding equipment, a transformer ratio of 10.6 is needed. In order to provide the voltage that corresponds to full load conditions $(25 \mathrm{~V} / 40 \mathrm{~A})$, the standard topology should operate with a dutycycle smaller than $50 \%$, whilst in the proposed topology, the H-bridge inverter can continue operating with $50 \%$ dutycycle, with the buck stage converter being exposed to operation with low dutycycle. It is clear that since the $\mathrm{H}$-bridge inverter in the proposed topology operates with less than half the DC-link voltage, in case it will switch with the same switching frequency and the same amount of primary current, it will produce less switching losses than the standard topology.

\section{A. H-bridge Performance}

Fig. 4 and 5, the waveforms of the current and voltage in the primary of the transformer in the case the welding supply has to deliver full load current (40 A) and voltage (25V) are shown. The standard circuit has a 3-level stepped voltage input into the transformer mainly because the zero voltage state it needed to impose additional loss in the load voltage. This also causes unwanted harmonics in the transformer magnetic flux, which may cause additional core losses. The current in the primary has a trapezoidal shape with a peak value of $4 \mathrm{~A}$.

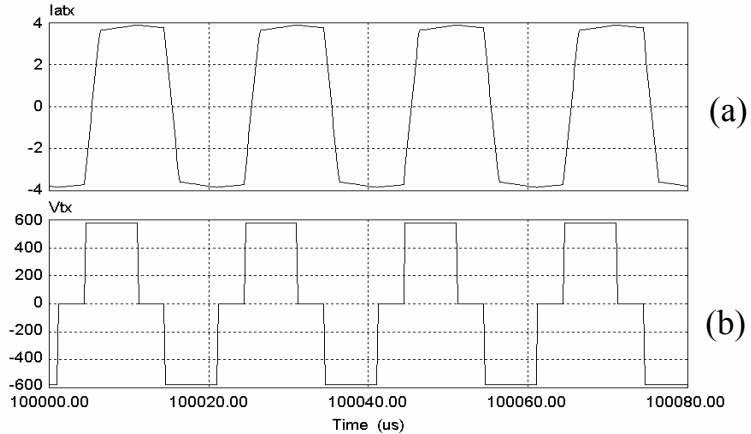

(a)

Fig. 4. Transformer primary winding current and voltage (Standard circuit).

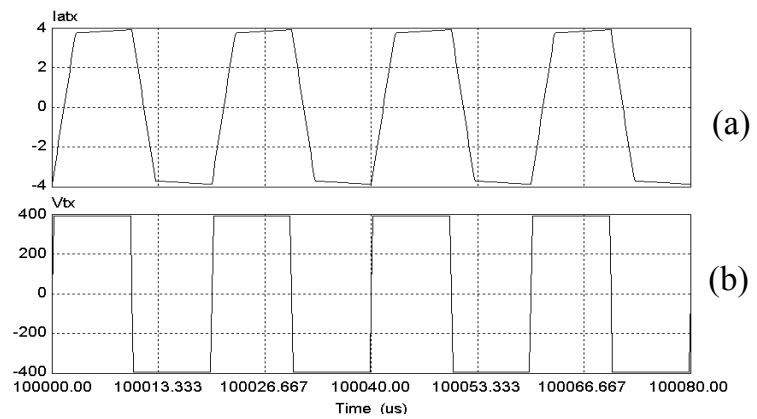

Fig. 5. Transformer primary winding current and voltage, (Proposed circuit).

The benefit of having a buck converter before the H-bridge converter is revealed in Fig.5a, where the switching voltage is effectively halved for this particular application. The proposed circuit provides a two-level square voltage waveform (which also makes it suitable to employ only a half bridge inverter and therefore to save some into the transformer and because the amplitude of the voltage is reduced by the buck converter, it generates far smaller fundamental + harmonics voltage components that cause losses in the core, and therefore can provide additional savings in core losses (not investigated here).

\section{B. An nsight into the H-bridge switching}

Fig. 6 and 7 show the voltage across and the current through one of the H-bridge inverter switches (assembly of a transistor and its antiparallel diode, or in case of MOSFET devices, the body diode that has quite bad switching behavior). Because at full load, the voltage delivered to the load is low (typically below $50 \%$ of the no-load voltage), the standard single stage DC/DC converter has to operate with reduced duty-cycle (the width of the positive voltage pulse is approx. $25 \%$ of the switching period). The switching frequency for the H-bridge inverter was set to $50 \mathrm{kHz}$; the transformer has typically set larger than normal magnetizing and leakage inductances to highlight the differences between topologies.

The positive current indicates that the transistor is conducting and the negative current indicates that the body diode is conducting. Both plots show that the device switches on at zero current because at the time the oposite transistor is switched off, all the primary winding current which lags the voltage, would commutate to the antiparallel diode. Thus, the ZCS (zero current switching) mark on the plot. The primary winding needs reverse voltage to be applied to it in order to make the current to change sign (and flow through the 
transistor that received gating signal). This is the reason why, for the standard topology, the antiparallel diode has to conduct during the whole duration of the zero voltage state of the $\mathrm{H}$ bridge inverter because zero voltage (shortcircuit of the primary winding) maintains the magnetic flux in the transformer. For the proposed topology, the conduction of the antiparallel diode and therefore its current rating (and size) is minimized which is an aspect that would help reducing the cost of the semiconductors even facilitating the use of the body diodes in MOSFET devices (zero added cost), diodes that can potentially increase the conduction losses, but not if they have to handle current only for very short period of time. The fact that the proposed circuit switches less voltage than the standard circuit, will allow for a reduction in the semiconductor switching losses and of the transformer core losses by approx $50 \%$. This allows to compensate fully or partly, depending on the switching frequency, the additional losses (conduction and switching in the IGBT and diode and core losses in the core of the buck inductor) caused in the buck converter.

These added losses are not high anyway, as the buck transistor might switch typically with only $10 \%$ of the $\mathrm{H}-$ bridge switching frequency. Also, even though it will switch the same voltage level as the switches in the standard topology (Fig. 8a), its current is significantly smaller because of the in/out power balance (2.5A in average as seen in Fig. $8 \mathrm{~b}$ ).

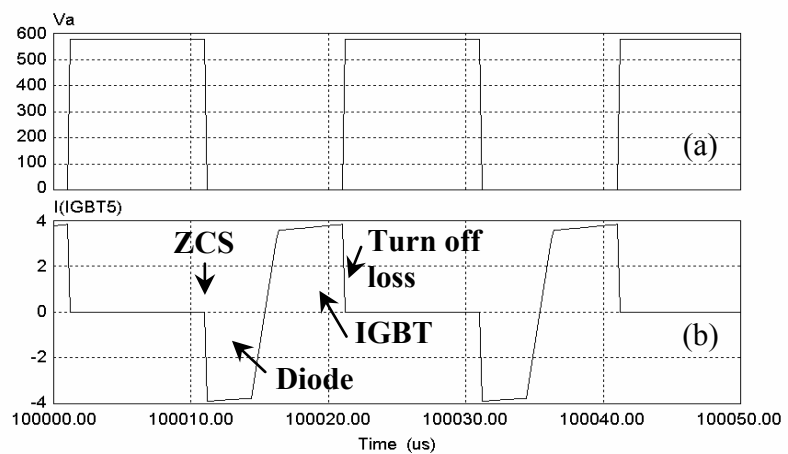

Fig. 6. a) Voltage across and b) current in an IGBT (positive current) + antiparallel diode (negative current) switch group of the H-bridge inverter (single-stage standard topology) (time scale $=10 \mu \mathrm{s} / \mathrm{div}$ ).

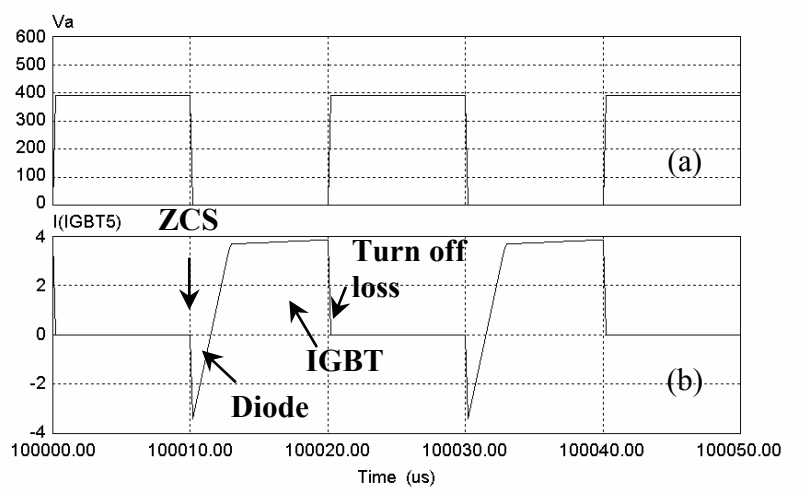

Fig. 7. a) Voltage across and b) current in an transistor (positive current) + antiparallel diode (negative current) switch group of the H-bridge inverter (two-stage topology) (time scale $=10 \mu \mathrm{s} / \mathrm{div}$ ).

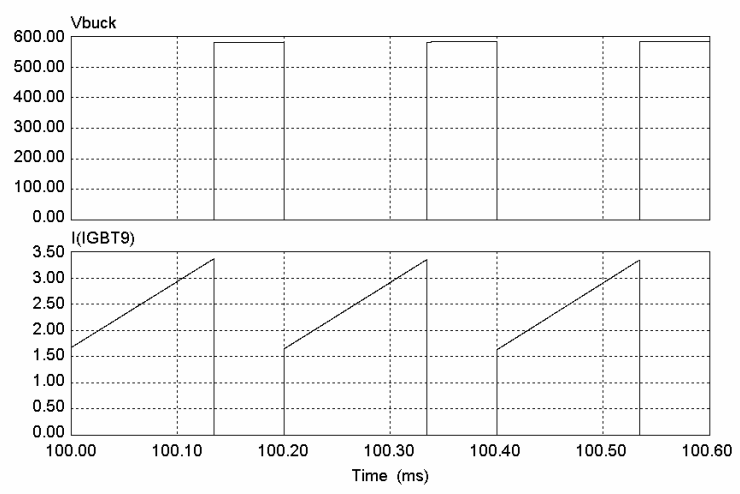

(a)

Fig. 8. a) Voltage across and b) current in the buck transistor for the proposed two-stage circuit (time scale $=0.1 \mathrm{~ms} / \mathrm{div}$ ).

Since there is no need to provide a certain current ripple, the design of the buck inductance may be oriented towards minimizing its size and cost (cheaper material that allows higher saturation flux density may be used since the switching frequency is low) and therefore allowing much higher current ripple, up to the discontinuous current mode boarder. Even though in this situation, the RMS current into the switch will require a larger device, the effect on the switching losses is opposite since most IGBTs produce lower energy loss during a turn-off than during a turn on at same current and voltage switched. Since the sum of the turn-on and turn-off current is constant and equal to twice the average current, and because the converter would operate near discontinuous current, it will switch very little current at turn-on, therefore would save more energy during turn-on than additional lost during turn-off.

In Table I, a comparison of the loss distribution incurred in the two converter topologies is presented. The following parameters are considered: $\mathrm{V}_{\mathrm{dc}-\mathrm{HB}}=577 \mathrm{~V}($ standard $) / 369 \mathrm{~V}($ new) H-bridge inverter: $\mathrm{R}_{\mathrm{ds}}=0.1 \Omega$ (MOSFET); $\mathrm{V}_{\mathrm{f}-\mathrm{hb}}=1 \mathrm{~V}$ (diode); $\mathrm{t}_{\text {on }}=150 \mathrm{~ns} ; \mathrm{t}_{\text {off }}=100 \mathrm{~ns} ; \mathrm{f}_{\mathrm{sw}-\mathrm{hb}}=35 \mathrm{kHz} ;$ Buck conv: $\mathrm{V}_{\text {ce-sat }}=2.5 \mathrm{~V}$ (IGBT); $\mathrm{V}_{\mathrm{f}-\mathrm{b}}=1 \mathrm{~V}$ (diode); $\mathrm{t}_{\mathrm{on}}=300 \mathrm{~ns} ; \mathrm{t}_{\mathrm{off}}=200 \mathrm{~ns} ; \mathrm{f}_{\mathrm{sw}-\mathrm{b}}=5 \mathrm{kHz}$;

TABLE I. POWER LOSS Distribution IN SEMICONDUCTORS

\begin{tabular}{|r|c|l|r|r|c|}
\hline & Transist & Diode & \multicolumn{1}{c|}{ ON } & \multicolumn{1}{c|}{ OFF } & \multicolumn{1}{c|}{ Loss } \\
\hline Standard & $1.34 \mathrm{~W}$ & $3.01 \mathrm{~W}$ & $0 \mathrm{~W}$ & $15.75 \mathrm{~W}$ & $\mathbf{2 0 . 1 0} \mathbf{~ W}$ \\
\hline Buck stage & $4.38 \mathrm{~W}$ & $0.87 \mathrm{~W}$ & $0.82 \mathrm{~W}$ & $1.00 \mathrm{~W}$ & $7.07 \mathrm{~W}$ \\
\hline HB Inverter & $2.16 \mathrm{~W}$ & $0.51 \mathrm{~W}$ & $0 \mathrm{~W}$ & $10.07 \mathrm{~W}$ & $12.74 \mathrm{~W}$ \\
\hline Proposed & $6.54 \mathrm{~W}$ & $1.38 \mathrm{~W}$ & $0.82 \mathrm{~W}$ & $11.07 \mathrm{~W}$ & $\mathbf{1 9 . 8 4} \mathrm{W}$ \\
\hline
\end{tabular}

It can be noted that the operating point chosen $(35 \mathrm{kHz})$, for calculating the losses gives almost identical total power loss for both topologies. However, the proposed converter experiences higher conduction losses: $7.92 \mathrm{~W}$ for the proposed compared to $4.35 \mathrm{~W}$ for the standard but lower switching losses: $11.87 \mathrm{~W}$ for the proposed compared to $15.75 \mathrm{~W}$ for the standard $(25 \%$ reduction). Since the overall losses are almost the same at 35 $\mathrm{kHz}$, it means that above this operating point, the proposed converter topology will be more efficient than the standard one, whilst below this point, the standard converter is more efficient. 


\section{An insight into the load side filtering requirements}

Due to the fact that the H-bridge inverter for the proposed two stage solution operates with $50 \%$ duty-cycle, it provides a rectified voltage on the output side with a smaller ripple. This has been reduced compared to the standard case but cannot be completely removed since during voltage polarity change, the transformer flux reverses sign which causes a gap in the rectified voltage which can be seen by comparing the ripple in the load side inductance current and the output voltage shown in Fig. 9a and Fig. 10a. The output LC filters were identical. By being able to reduce the output ripple, less inductance is required in the output filter. A similar observation but less significant reduction may be seen in the output voltage (Fig. 9b and $10 \mathrm{~b})$.

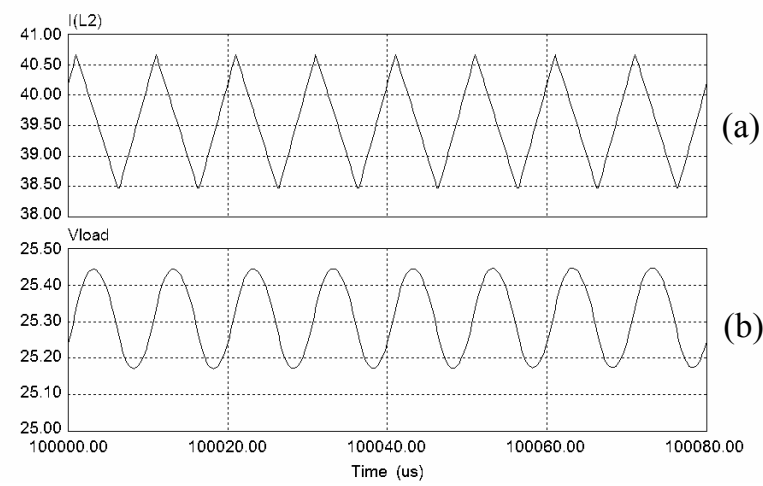

Fig. 9. Output inductor current and load voltage (standard circuit).

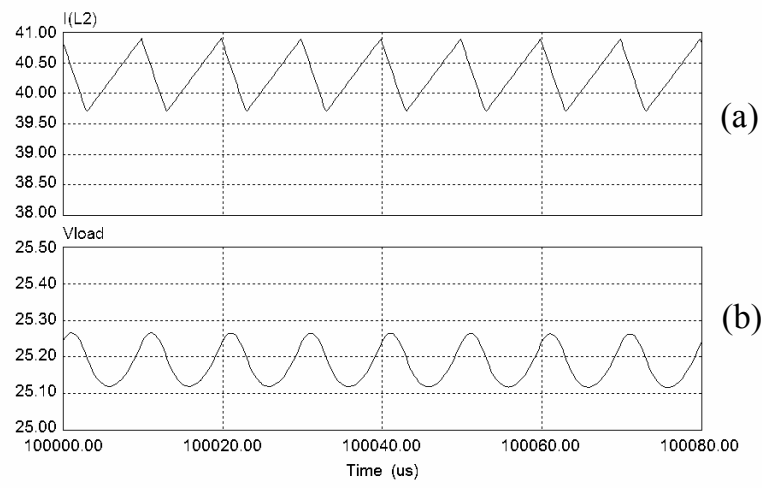

Fig. 10. The output inductor current and load voltage (proposed circuit).

\section{EXPERIMENTAL RESULTS}

A small scale prototype of the two-stage power converter has been built to prove the principle as part of a final year student project. The DC-link terminals of the H-bridge inverters were made available via external connectors so that power could be fed directly to allow a straightforward comparison of the standard solution against the proposed one, whilst all the components in the power stage remain the same. The parameters of the experimental setup were: $\mathrm{V}_{\text {in }}=90 \mathrm{Vdc}$; $\mathrm{L}_{\text {buck }}=2.4 \mathrm{mH} ; \mathrm{f}_{\text {sw-buck }}=5 \mathrm{kHz} ; \mathrm{N}_{\mathrm{p}} / \mathrm{N}_{\mathrm{s}}=10: 1 ; \mathrm{f}_{\mathrm{sw}-\mathrm{HB}}=50 \mathrm{kHz}$; $\mathrm{t}_{\text {dead-time }}=50 \mathrm{~ns} ; \mathrm{L}_{\text {out }}=47 \mu \mathrm{H} . \mathrm{R}_{\text {load }}=4.4 \Omega$. Two operating modes and corresponding methods to generate the gate signals for the H-bridge inverter transistors were used:

- "standard" having adjustable phase shift between the corresponding gating signals of the inverter legs;

- "proposed" adjustable DC-link voltage provided by a buck stage and constant 180 degrees phase shift between the corresponding gating signals of the inverter legs.

Fig. 11 shows the primary transformer voltage and the rectifier voltage delivered at the output of the secondary winding and across the load. Due to a high parasitics of the power stage layout, quite large ringings appear in the rectified voltage that can potentially cause EMI. The filtering effect of the output inductor smoothing is reflected in a $2 \mathrm{~V}_{\mathrm{pk}-\mathrm{pk}}$ load voltage ripple. Fig. 12 shows the same results for the proposed two-stage solution. Since the primary transformer voltage is a pure square wave, less voltage is needed to deliver the same output power. The slight oscillation during the zero crossing is caused by the dead-time needed to secure safe commutation of the switches within a leg//overlap commutation of the secondary side rectifier diodes due to the transformer leakage inductance. Since the primary voltage is now smaller in amplitude, smaller ringings in the rectified secondary voltage appear, which would cause less EMI problems compared to the standard solution. Since there is a very small gap in the rectified voltage/current delivered by the secondary, which is

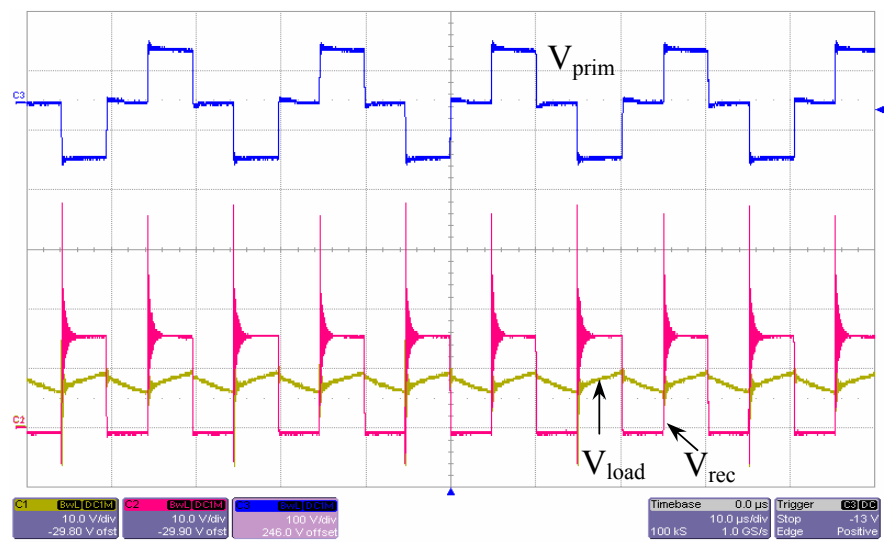

Fig. 11. Experimental results for standard DC/DC converter: the primary voltage $\mathrm{V}_{\text {prim }}[100 \mathrm{~V} /$ div $]$; the rectified $\mathrm{V}_{\text {rec }}$ and the load $\mathrm{V}_{\text {load }}$ voltages [10V/div]. Time scale: $10 \mu \mathrm{s} / \mathrm{div}$.

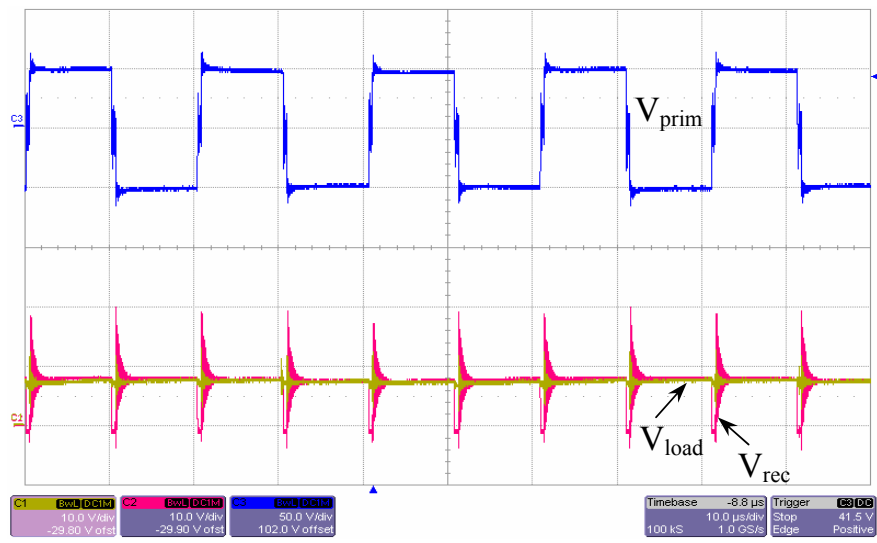

Fig. 12. Experimental results for the two-stage DC/DC converter: the primary voltage $\mathrm{V}_{\text {prim }}[50 \mathrm{~V} /$ div $]$; the rectified $\mathrm{V}_{\text {rec }}$ and the load $\mathrm{V}_{\text {load }}$ voltages [10V/div]. Time scale: $10 \mu \mathrm{s} / \mathrm{div}$. 
caused by the fact that a short zero voltage state is actually produced on the primary winding during the commutation of the H-bridge inverters (caused by the deadtime)/overlap commutation of the rectifier diodes due to the transformer leakage inductance, this reflects in a much smaller ripple in the load voltage and current, since the Volt-time-area that causes current ripple in an inductance is insignificant. This will further allow for the reduction of the size of output inductor filter for a given ripple limitation.

Fig. 13 shows a close up of the commutation process of one of the H-bridge inverter switches (transistor and its antiparalel diode). It is clear now that the assumptions made when dealing with the simulation results are true: the turn off commutation causes losses because the collector emitted voltage starts rising whilst the switch is still conducting current; the turn on is soft because the collector emitted voltage collapses first before the current actually start building up in the device. Due to the combination of very small leakage inductances in the high frequency transformer, a very small deadtime and a rather large parasitic capacitance in the circuit, there is no obvious transition from transistor to opposite diode conduction, as seen in the simulation results.

\section{CONCLUSIONS}

The switching losses in the proposed two-stage DC/DC converter topology are reduced significantly, especially in the H-bridge stage, due to the minimization of the switching voltage, whilst there is only a slight increase in losses to accommodate the buck stage. Due to the square wave input as opposed to the stepped input, the proposed circuit is able to better utilize the H-bridge semiconductors and magnetic materials (lowest crest factor), whilst requiring smaller output filtering. Savings in the output inductor which operates at much higher switching frequency than the buck stage inductance, would offset the cost of the additional buck inductance since the output inductance would normally require more expensive core materials and winding technologies. The full potential of this topology can only be explored by considering full size reduction of all passive components due to much higher switching frequency in conjunction with the particularities of the application.

From the results shown there is a clear reduction in losses of the two-stage converter when operating at high frequencies. As well as the reduction of power losses occurring during the application, manufacturing gains are to be made through the reduction in size of large elements. The reduction of expensive components such as iron for the core and copper for winding may offset the cost of additional transistor, diodes and capacitors, reducing the overall size and cost of the power supply.

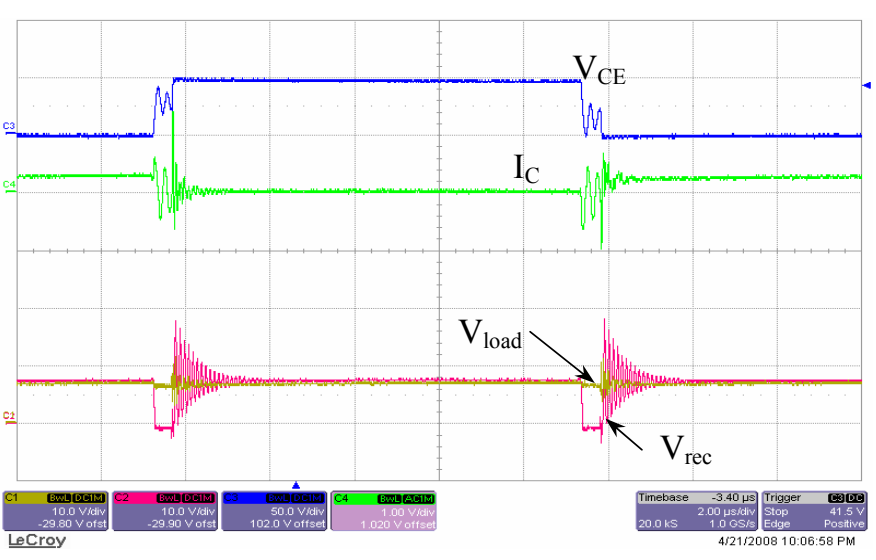

Fig. 13. Experimental results for the commutation within the H-bridge switches of a two-stage DC/DC converter: the collector-emitter voltage $\mathrm{V}_{\mathrm{CE}}$ $[50 \mathrm{~V} / \mathrm{div}]$; the collector current $[1 \mathrm{~A} / \mathrm{div}]$; the rectified $\mathrm{V}_{\text {rec }}$ and the load $\mathrm{V}_{\text {load }}$ voltage $[10 \mathrm{~V} / \mathrm{div}]$. Time scale: $2 \mu \mathrm{s} / \mathrm{div}$.

\section{REFERENCES}

[1] American Welding Society, Edison Welding Institute, US Bureau of Export Administration, et. al., Welding-related Expenditures, Investments and Productivity Measurement in US Manufacturing, Construction and $\begin{array}{lll}\text { Mining Industries, } & 2002 .\end{array}$ http://www.weldinginfocenter.org/econ/welding related expenditures.pdf

[2] N. Mohan, T, Undeland and W. Robbins, Power Electronics: Converters Application and Design. New York, Wiley, 1996.

[3] K. Weman, Welding Process Handbook, Cambridge: Woodhead Publishing Limited, 2003, pp.13-25.

[4] F.G. Armao, Inverter Based Welding Power Supplies for Welding Aluminum, The Lincoln Electric Company, July 2003. http://www.lincolnelectric.com/knowledge/articles/content/inverter.asp

[5] Theron, P.C.; Ferreira, J.A.; Heavy duty inverter welders with high overvoltage immunity, Proc. of AFRICON'96, Vol. 1, pp. 221-225, 1996.

[6] Chae, Y.-M.; Gho, J.-S.; Choe, G.-H.; Shin, W.-S.; Choi, J.-Y.; PWM converter-inverter arc welding machine using new type NCT, Proc. of IEEE PESC'98, Vol. 2, pp. 1636 - 1641, 1998.

[7] Zhu Jinhong; Liang Wenlin; Shi Yaowu; Study on the dynamic process of arc welding inverter, Proc. of EPE-PEMC'00, Vol. 1, pp. 308-311, 2001.

[8] Chae, Y.-M.; Gho, J.-S.; Mok, H.-S.; Choe, G.-H.; Shin, W.-S.; A new instantaneous output current control method for inverter arc welding machine, Proc. of IEEE PESC'99, Vol.1, pp. 521 - 526, 1999.

[9] Huang Ji-Qiang; Chen Shu-Jun; Yin Shu-Yan; Wang Dong-Ping; Zeng Hua; A novel three-phase welding inverter power supply with high power factor, Proc. of Industrial Technology, Vol. 2, pp. 1113 - 1118, 2003.

[10] C. Klumpner, A New Two-Stage Voltage Source Inverter with Modulated DC-link Voltage and Reduced Switching Losses, Proc. of IEEE IECON'06, pp. 2208-2213, 2006. 